\title{
Patients' attention to and understanding of adverse drug reaction warnings
}

This article was published in the following Dove Press journal:

Patient Intelligence

10 December 2010

Number of times this article has been viewed

\section{Tresa Muir McNeal' \\ Colleen Y Colbert ${ }^{\prime}$ \\ Christian Cable' \\ Curtis R Mirkes' \\ June G Lubowinski² \\ John D Myers'}

'Department of Medicine, Texas A\&M University System HSC College of Medicine, Scott \& White Healthcare, Temple, TX, USA; ${ }^{2}$ RD Haynes Medical Library, Scott \& White Healthcare, Temple, TX, USA
Correspondence: Tresa Muir McNeal Scott \&White Hospital, Dept of Internal Medicine, 240 I South 3 Ist St, Temple, TX 76508, USA

Email tmcneal@swmail.sw.org
Introduction: Medications are critical to the management of patient conditions, and they can have significant effects on the success or failure of medical interventions. Patient perceptions of drug warnings play an important role in medication compliance and ultimately disease management. Several factors may affect patients' understanding of drug warnings and drug labeling, including health literacy and interactions with physicians and pharmacists.

Purpose: The purpose of this article is to provide a review of the literature related to patient perceptions of drug warnings and drug labeling. Descriptive articles and studies regarding patient perceptions and knowledge of adverse drug reaction warnings were reviewed.

Methods: The following databases were utilized to search the literature related to patient perceptions of drug warnings: PubMed, Academic Search Premiere, CINAHL, Medline, Psych Info, Business Source Complete, Alternative Healthwatch, Health Source (both Nursing/Academic and Consumer additions), JSTOR, and Master File Premiere. For the purpose of this review, any peer-reviewed article was eligible. Exclusionary criteria included: articles published in languages other than English, articles/studies on patient perceptions of vaccines and chemotherapy, and articles related to perceptions of medications administered in the inpatient setting. Forty-six articles were included in the review.

Results: Health literacy has been shown to have a major impact on patients' ability to understand potential adverse reactions and instructions on correct dosing of medications. Direct communication with physicians and pharmacists is one of the most important and effective variables in promoting understanding of drug warnings. Appropriateness of written medical information that is informative and timely can improve patients' perceptions of drug warnings and hopefully disease management.

Conclusion: As patients increasingly assume more personal responsibility as informed consumers of health care, it is even more important to address patient perceptions of drug warnings considering how this fits in the context of their overall care.

Keywords: patient perceptions, adverse drug reaction warnings, health literacy

\section{Overview}

One third of the 1.5 million adverse drug events that occur in the United States each year are in the outpatient environment. Patients' perceptions of drug warnings and their interpretations of written drug information are critical issues facing medicine today. In a world of exponentially greater medication options, effective communication of drug information has become more important than ever before. The Institute of Medicine has gone so far as to identify the provision of appropriate drug warnings as a priority in its mission to promote patient safety. ${ }^{1}$ 
Most patients want to understand their medications and administer them safely and appropriately. Several issues, such as administering the doses at the correct times and being aware of potential adverse effects, prove to be challenging to patients. Patients' knowledge and attitudes toward drug warnings are important factors in medication compliance. It has been documented that patients frequently misinterpret prescription labels and drug information, leading to inappropriate administration. ${ }^{2}$ This can prove frustrating for health care providers and patients, and improvement requires a multifaceted examination of the issues faced by patients.

The purpose of this article is to provide a review of the literature related to patient perceptions of drug warnings and drug labeling. Descriptive articles and studies regarding patient perceptions and knowledge of adverse drug reaction warnings were reviewed. A brief background section on the significance of adverse drug events is presented, followed by the review. Suggestions to improve patient education concerning drug information will be presented.

\section{Background}

\section{Significance of adverse drug events}

An estimated four out of five adults in the United States use at least one medication in any given week. ${ }^{1}$ In the US, nearly one-third of patients use at least five different medications per week. ${ }^{1}$ Due to the frequency of medication use and potential for errors in administration, the risk of adverse effects is great. Adverse drug events (ADEs) include both errors of administration as well as adverse drug reactions (ADRs). According to the World Health Organization, an ADR is a noxious, unintended, and undesired effect of a drug, which occurs at doses used in humans for prophylaxis, diagnosis, or therapy. ${ }^{3}$ ADEs due to medication errors within hospitals are associated with 770,000 injuries or deaths each year in the US. ${ }^{4}$ ADEs among hospitalized patients cause an average prolonged hospitalization of 1.2-3.8 days. ${ }^{5}$ A meta-analysis by Lazarou et al, involving the search of four electronic databases for articles published between 1966 and 1996, evaluated 39 prospective studies for incidence of inhospital ADRs and ADRs prompting hospitalization. ${ }^{6}$ The overall incidence of ADRs was 6.7\%, based upon studies conducted at US hospitals. Fatal ADRs represented $0.32 \%$ of hospital cases, making ADRs the fourth to sixth leading cause of death. ${ }^{6}$

Several studies have examined the link between adverse drug events or reactions and subsequent hospital admissions, with troubling findings. A Canadian retrospective study found that $42 \%$ of patients with ADEs required hospitalization, and an estimated $29 \%$ of ADEs were considered preventable. ${ }^{7}$
Increasing age, comorbidities, and medications were found to increase prevalence of ADEs. Cardiovascular drugs were the most common drugs to result in ADEs. ${ }^{7}$ In Britain, a prospective study of 18,820 patients admitted to the British National Health System revealed that $6.5 \%$ of hospital admissions were related to ADRs. ${ }^{8}$

While most research has focused upon in-hospital ADEs, ${ }^{9}$ targeting ADEs in the ambulatory setting has also become a focus of research and intervention efforts. Rodriguez-Monguior et al, in a review examining the economic impact of ADEs in the US and other countries, reported that an estimated $43.3 \%-83 \%$ of outpatient ADEs are preventable. ${ }^{5}$ Thus, patients' awareness of ADEs and understanding of drug warnings in the ambulatory setting is critical and can potentially prevent emergency department visits and acute hospitalizations.

\section{Methods}

\section{Search strategy}

An initial PubMed search yielded 649 citations when utilizing the search terms "patient perceptions" AND "adverse drug reactions". Of the 649 citations, 623 (96\%) were unrelated to the general topic of this review and instead were associated with drug toxicity and other subjects. Only 26 (4\%) were generally associated with the subject matter of this review. Exclusionary criteria included: articles published in languages other than English, articles/studies on patient perceptions of vaccines and chemotherapy, and articles related to perceptions of medications administered in the inpatient setting. Of the 26 citations, 8 (31\%) dealt with perceptions of health care professionals (rather than patients) to adverse drug reactions or drug reaction warnings, leaving 18 (69\%) articles eligible for inclusion. Additional searches utilized the following databases: Academic Search Premiere, CINAHL, Medline, Psych Info, Business Source Complete, Alternative Healthwatch, Health Source (both Nursing/Academic and Consumer editions), JSTOR, and Master File Premiere. For the purpose of this review, any peer-reviewed article was eligible. The following search terms were utilized: "pharmaceutical preparations/adverse effect," "drug labeling," "patient education," "patients AND drug warnings," "health literacy," and "drug labeling” AND "medication adherence". Additionally, using PubMed, a search with "patients" MeSH AND "health literacy" MeSH was run. All search lists were cross-referenced, yielding articles eligible for inclusion. In addition, reference lists from relevant articles were checked by TM and CYC, which yielded additional articles that had not surfaced in other searches. A total of 46 articles were included in this review. 


\section{Results}

Based upon this review of the literature, there are numerous factors that may contribute to patients' perceptions of drug warnings. One of these factors, health literacy, can be classified as patient-centric, while others may relate to stakeholders within the health care system such as pharmaceutical manufacturers, physicians, and pharmacies. Readability/ comprehensibility of medication inserts; physician communication with pharmacists; physician communication with patients; and patients' own literacy levels all affect patients' understanding of and attitudes toward drug reaction warnings. What follows are brief summaries of the literature in these areas.

\section{Medication information}

Currently, there is a lack of standardization of consumer medical information about potential adverse pharmaceutical events. Distracting marketing information and logos on both prescription and over-the-counter medications can unwittingly downplay important drug information. The complexity of written medication information, including drug labels, can often be a hurdle for even the most educated patient.

\section{Written medication information}

Several studies have analyzed medication leaflets and other written medication information (WMI) for quality, readability, and comprehensibility. ${ }^{10-14}$ Carrigan et al assessed leaflets from 50 of the most commonly prescribed drugs in the United Kingdom, with half of the leaflets representing generic medications and half representing brand-name medications. ${ }^{10}$ Researchers found immense variability in the presentation of information, and $40 \%$ of leaflets gave no indication of the likelihood of ADEs occurring. In addition, more than half of the leaflets presented adverse effects in paragraphs of continuous text, without any form of categorization as to types of adverse events. Only $12 \%$ used currently recommended European Union (EU) terms and 8\% of leaflets provided numerical information regarding risk, despite current best practice recommendations on presenting verbal descriptions and numerical information in the form of natural frequencies. Only two leaflets (4\%) included any information regarding benefits of the medication. ${ }^{10}$ Fuchs et al, in a study of package inserts in Germany, noted that of $73.5 \%$ of medication inserts studied, the maximum daily dose was missing. ${ }^{11}$ It was also noted that $98.5 \%$ of package inserts included nonquantifiable statements such as "take 1-2 tablets, 1-3 times daily". ${ }^{11}$ Evaluating the quality of WMI is important, but ensuring WMI is actually given to the patient is even more critical. A recent US study evaluated 83 medication samples for suitability and readability of WMI. These samples were obtained from outpatient clinics at four large teaching hospitals. No WMI was presented with the drug sample $46.9 \%$ of the time. ${ }^{2}$ When WMI was included, it was written at a reading level higher than that of the average American adult. ${ }^{12}$

The importance of color-coded type has also been evaluated using patient questionnaires. ${ }^{14}$ Researchers found the majority of patients $(65.7 \%)$ did not like colored WMI. However, within the total group surveyed, specific colors were believed to represent distinct groups of information, such as side effects or contraindications. Patients chose red to convey side effects and red or black to convey contraindications. ${ }^{14}$ Concerning colors, the same has been noted regarding medication labels, as patients often assign meaning to colors on specialized pharmacy labels, believing red labels are "extremely important" and yellow less important. ${ }^{2,14}$

\section{Adhesive medication labels}

Drug labels are an important component of written medication information. They have been identified as a possible cause of medication errors. ${ }^{15,16}$ Studies have suggested that drug labels using simple text and simple text in conjunction with icons are more likely to promote patient comprehension. ${ }^{17,18}$ It has also been noted that with increased numbers of warning labels, comprehension of and attention to medication warnings decreases. ${ }^{17}$ Because of this, it may be reasonable to limit adhesive medication labels to only the one or two most important messages regarding the drug. ${ }^{17}$ The overall theme in development of both WMI and adhesive drug labels should be simplicity and lack of clutter, making the information more inviting to view. ${ }^{19}$

The association between drug labels and ADEs precipitating hospitalization or visits to the emergency department has come under scrutiny, ${ }^{1}$ but the results of studies have been equivocal. In a study with patients who utilize Target pharmacies in Minnesota and New Jersey, the potential benefits of a newly designed drug label on health outcomes were evaluated..$^{20}$ Patients were provided a label with increased surface area, larger font for directions and warnings, and more white space. In addition, family members' medications were color-coded to minimize errors. Matched control patients from non-Target pharmacies were compared for health outcomes. No benefit was found with the new label in terms of preventing emergency department visits and inpatient outcomes due to ADEs. ${ }^{20}$ 


\section{Physician/pharmacist communication of drug information}

Studies focusing on improving WMI for patients with limited health literacy have shown little benefit in terms of patient outcomes. Researchers have therefore called for improved communication between providers and patients. ${ }^{20-22}$ It is not surprising that when compared with other sources of medical information (ie, media, pharmacists, nurses, WMI), patients valued most highly the information communicated by their primary care physicians. ${ }^{23}$ In a UK survey examining this issue, it was noted that physicians actually spent less time with patients of lower socioeconomic status and provided them with less medical information. ${ }^{23}$

In parts of Eastern Europe, parts of Asia, Central America, and many Arabian Gulf countries, the majority of medications are dispensed over-the-counter. In this setting, patients may rely more heavily on pharmacists to guide them in understanding indications for medication use, as well as expected adverse drug reactions. ${ }^{24}$ In Qatar, a survey of patients $(\mathrm{n}=570)$ filling medications at one employer's private medical clinic evaluated pharmacists' roles in guiding over-the-counter medication use, as well as patient preferences for over-the-counter medication indications. The majority of patients understood pharmacists' roles in guiding them to a particular drug for a specific indication at the point of sale. ${ }^{24}$ Another study in Iran, however, surveyed patients $(n=671)$ at 19 outpatient pharmacies and discovered that only $46 \%$ of patients were informed by their pharmacists about frequency and dosage for their medications. ${ }^{25}$

\section{Patient attitudes/perceptions}

For patients to maximally benefit from drug information, it is important to address their attitudes toward medications, their understanding of medications, and the source of information most often being utilized. ${ }^{26,27}$ If drug information is not easily comprehensible and useful to patients, it is a failure. ${ }^{14}$ Nader et al found that a large percentage of patients surveyed at outpatient pharmacies in Shiraz, Iran never looked at the WMI associated with their medications. ${ }^{25}$ Those who were college educated used WMI more frequently than those patients without a college education. Bernardini et al also studied patients' attitudes toward package leaflets with a survey conducted at outpatient pharmacies. ${ }^{27}$ Researchers reported that $83.5 \%$ of Italian patients surveyed $(n=1004)$ noted they regularly read package leaflets, but $53.3 \%$ found the information difficult to understand. In looking for specific information in the leaflet, $46.9 \%$ of patients could not easily find information for which they were looking. The majority of respondents (74.3\%) noted symbols and pictograms were helpful in locating specific information. ${ }^{27}$

In a UK qualitative study utilizing focus groups and structured interviews, researchers investigated patients' ( $n=32$ ) knowledge of side-effects of OTC medications. ${ }^{26}$ All patients had received medication information leaflets, but only three had actually read the leaflets. The majority of patients reported receiving drug information from pharmacy assistants, physiotherapists, friends, work colleagues, books, the media, the internet, family, pharmacists, and doctors rather than the medication leaflets. Several patients expressed frustration with leaflet information, which might contain long lists of side effects that could 'scare' patients or cause them to develop a side effect based on suggestion. Most patients who had experienced a side effect were able to identify the link between the medication and the symptom based upon the timing of the reaction. ${ }^{26}$

In Belgium, with a literacy level of 95\%, a survey $(n=398)$ was performed to determine the attitude of the Belgian public toward WMI. Of the $89 \%$ of survey participants who read the WMI, $86 \%$ found the information useful, but $72 \%$ found it difficult to remember. Sixty-nine percent wanted more graphic illustration. Regarding confidence produced by WMI, $25 \%$ of patients did not think WMI enhanced their confidence in the medication, and $31 \%$ stated the WMI made them afraid to use the medicine. ${ }^{28}$ This study was performed just before new Belgian laws went into effect requiring patient-centered information to be provided. ${ }^{28}$

In considering patients' perceptions of drug warnings, it is also important to consider patients' perceptions of medication risk in general. A study by Cullen et al assessed consecutive patients $(\mathrm{n}=399)$ admitted to Beaumont Hospital in Dublin, Ireland in the months of September 2003 and May 2003. ${ }^{29}$ Patients were included in the study if they were taking one or more of the study medications, including: aspirin, proton-pump inhibitors (PPIs), warfarin, nonsteroidal antiinflammatory drugs (NSAIDS), and corticosteroids. Patients appropriately ranked corticosteroids and warfarin as unsafe medications, but often underestimated the risks associated with these drugs. NSAIDs were ranked almost as safe as PPIs, and patients identified gastrointestinal (GI) ulceration with risk of hemorrhage as the most common ADR associated with NSAIDs, but underrated the risk of the ADR. Interestingly, PPI users ranked gastritis as an adverse drug reaction for PPIs, indicating a lack of understanding of the indication for using this medication. ${ }^{29}$ These scenarios point to the benefit of providing drug information that is user-friendly and concise in order to better educate patients. 
The manner in which patients evaluate WMI and determine its usefulness is associated with individual patient characteristics, ${ }^{30}$ such as age and health literacy. In an Australian study examining patient characteristics that influence evaluation of WMI, 479 patients completed structured questionnaires, which also included the short-form Test of Functional Health Literacy in Adults (S-TOFHLA) regarding their own prescribed medication instructions. Older patients and patients with increasing numbers of medications perceived WMI to be more helpful. ${ }^{30}$ Researchers speculated that younger patients completing questionnaires may have had higher expectations of the drug information and were consequently less satisfied. In this same study, health literacy influenced patients' comprehension of WMI and also the likelihood of using WMI in the future. ${ }^{30}$

\section{Health literacy and numeracy of patients}

Many studies point to low health literacy and low numeracy (ie, skill with numbers and mathematics) as a cause of impaired understanding of drug warning labels and subsequent inappropriate medication use..$^{2,17,21,31}$ Low literacy can lead to poor health outcomes secondary to medication noncompliance. ${ }^{21,32}$ Several studies suggest that health literacy alone is a predictor of medication adherence and medication knowledge. ${ }^{31,33,34}$ Unclear labeling and icons can contribute to patient frustration. ${ }^{2}$ In addition, extensive printed drug information written at a reading level higher than that of the average reader can also contribute to patient dissatisfaction

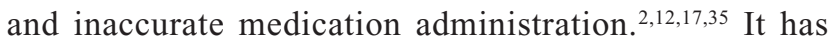
been noted that with decreasing levels of education ${ }^{27,36}$ and increasing numbers of prescriptions, ${ }^{36}$ the percentage of patients reporting lack of comprehension of WMI increases.

Utilizing qualitative methodology, Wolf et al evaluated patient misunderstanding of drug label instructions in patients $(n=395)$ at three different United States primary care outpatient clinics. ${ }^{35}$ Patients were interviewed and literacy was assessed with the Rapid Estimate of Adult Literacy in Medicine (REALM). Six themes surfaced as causes for patient misunderstanding of drug labels: label language, complexity of instructions, implicit versus explicit dosage intervals, presence of distractors, label familiarity, and attentiveness to label instructions. ${ }^{35}$

Patients with reading levels below 6th grade were unable to interpret common words on labels such as antibiotic (79\%), orally (73\%), teaspoonful (70\%), medication (48\%), prescription (45\%), and dose (35\%). Patients were asked to read and demonstrate understanding of dosage instructions for five common prescription medications. The ability to read dosage instructions is not always associated with comprehension of dosing instructions. ${ }^{35}$ When verbally given instructions to "take two tablets by mouth twice daily," and asked what the total number of pills per day would be, one third of patients could not state the correct answer. ${ }^{35}$ Even when patients could read labels and seemed to understand instructions, actual demonstration of comprehension was significantly lower. Both of these findings were more pronounced in patients with low literacy. ${ }^{35}$

In addition, limited English proficiency may affect interpretation of drug warnings. In a 2009 survey of pharmacies $(n=764)$ in four states in the US with fast-growing or large Latino populations, $34.9 \%$ of pharmacies reported that they were unable to provide any Spanish translations and 21.7\% were only able to provide limited translation services. This can significantly decrease appropriate medication compliance among this population. ${ }^{37}$

\section{Educating patients and physicians}

Patients' understanding of warning information and subsequent behavior

There is a critical balance in providing meaningful information and creating unwarranted fear when educating patients about medications. In the previously mentioned Belgian study, some respondents noted that package inserts made them fearful. ${ }^{28}$ In a US telephone survey $(n=1223)$ by Morris et al investigating the nature and source of information provided to patients regarding prescription drugs, $12 \%$ stated that they expected to have a drug side effect, but only $9 \%$ said that they actually experienced one. ${ }^{22}$ It was noted that if patients did experience a side effect, the most frequently cited action was to call their physician (40\%). In a more recent study, the US Military Health System evaluated trends in rosiglitazone use following safety warnings in 2007. This was a study of prescription drug fills among a cohort of beneficiaries with diabetes enrolled in TRICARE, the military's health insurance program. Overall, results showed patients and providers responded quickly to widespread negative information about rosiglitazone with the number of refills for rosiglitazone declining by more than $50 \%$ following warnings. ${ }^{38}$ In contrast, when Health Canada released three warnings (2002-2005) of increased risk of stroke or death in elderly patients with dementia who were taking antipsychotics, the rate of use of these drugs increased by $20 \%$ from the month prior to the first warnings in September 2002 through the end of the study in February 2007. ${ }^{39}$ Educating physicians regarding alternative treatments 
and the importance of advocating for vulnerable populations in these situations may be helpful.

\section{Physician education in providing appropriate drug information}

Physicians play a crucial role in the transmission of both written and verbal medication information to patients. It is therefore important for governing agencies to be able to communicate effectively and efficiently with health care providers as new problems arise with drugs or medical products. ${ }^{40}$ In a review by Goldman, passive interventions such as 'Dear Doctor' letters or other printed material alone are often ineffective in communicating product risk and ensuring practice improvement. ${ }^{40}$ Personal communication with physicians on a regular basis has shown benefit as evidenced in a study by May et al. ${ }^{41}$ In this study of Australian physicians $(n=210)$, one group receiving regular continuing education visits on therapeutics specifically related to minimizing risks of NSAID usage was compared with physicians not receiving this service. A significant reduction in NSAID usage was noted in the intervention compared to the control group ( $28 \%$ vs $9 \%)$, and there was a $70 \%$ reduction in hospital admissions for GI bleeds in the patients of intervention group physicians. ${ }^{41}$ The authors concluded that prescriber education was a factor in decreasing hospitalizations for NSAID-induced adverse effects. ${ }^{41}$ Clearly, effective education of physicians can in turn improve outcomes for patients.

\section{Discussion}

The challenge is to provide patients with meaningful, concise drug information and prevent ADEs. Suggestions for improvement (as noted in the studies reviewed) have focused upon physicians, who are at the helm of providing drug information to patients; drug manufacturers, who produce the medication inserts; pharmacists, who may provide counseling at the point of sale; and consumers (patients), with a focus on health literacy. Evaluation of the most effective means of communication is warranted given the issues surrounding medication usage (ie, drug-drug interactions/ contraindications, monitoring, side effects, off-label use, etc). Also, multiple modalities of communication with patients should be used whenever possible to improve patient understanding. ${ }^{40}$

\section{Development of standards/regulations}

There is a need for industry and/or governmental regulation in the area of WMI and patient warning labels. The goal would be to promote patient safety and useful knowledge regarding medications. ${ }^{2}$ In the United States, the Federal Food, Drug, and Cosmetic Act of 1938 gave the Food and Drug Administration (FDA) authority to oversee reform of drug labels and package inserts; however, adhesive warning labels were not considered within the scope of this act and have not been addressed. ${ }^{2}$ In Europe, the European Commission developed standards in 1992 stating that a package leaflet, directed at consumers and providing comprehensible information, must be included in packaging of medicinal products. $^{42}$ In 1998, another European Commission guideline on readability of the label and package leaflet updated this guideline. ${ }^{43}$ Despite these efforts, studies of package leaflets in the UK, Germany, and Italy reveal lack of compliance with overall recommendations and poor readability and comprehensibility among patients. ${ }^{10,11,27}$ Amendments to the 1998 European guidelines were most recently published in January of 2009 and specifically required patient participation in the development of patient information leaflets, as well as accommodations for Braille, and a standardized order and format for presentation of the information. ${ }^{44}$ Outcomes of these latest recommendations have not been reported yet.

In the United States, the Department of Health and Human Services, the FDA, the American Pharmacists Association, the American Society of Health-System Pharmacists, and the National Association of Boards of Pharmacy, collaborated in the development of the Keystone Dialogue in 1996. This resulted in recommendations to involve consumers in the development of package labels and inserts among other plans for improving available medication information. ${ }^{2,17,45}$ Thus far, minimal progress has occurred in improving and standardizing warning labels. ${ }^{17}$ Additional work is needed in the evolution of evidencebased standards to improve development of patient-centered prescription labels. ${ }^{17}$

\section{The pharmaceutical industry: WMI development}

Interpretation of written medical information will differ from patient to patient, and this must be considered when developing a plan to improve written information provided with medications. ${ }^{30}$ Prescription drug labels and WMI should use simple and concise language, with explicit doses and dosing intervals. ${ }^{35}$ It is most important for pharmaceutical companies to test WMI and drug labels with a representative patient sample to maximize comprehension and readability. ${ }^{2,11,13,17,27,30,46}$ Focus groups 
have been utilized in this effort ${ }^{46}$ and changes have been made based upon feedback from participants. The WMI and drug labeling products are then retested with a patient sample. This process has resulted in the development of much simpler text and icons for 10 common medication warning labels. ${ }^{46}$

\section{Suggestions for improvement of WMI}

The information provided in WMI is not the only important concept to be considered in its development. Appropriate font, large text, appropriate reading level, pictorial aids, and prominence of important warnings are all important for improving patients' perceptions of drug warnings. ${ }^{12,13,35} \mathrm{In}$ a study by Wolf et al, patients suggested the use of numeric symbols was preferable to the written word whenever possible (ie, "2" vs "two"). ${ }^{35}$ Patient leaflet design and layout are key aspects which may make information more appealing and more likely to be read. Appropriate use of white space, color text or pictures, and consistent use of headings and bullet points may also make information more inviting, although this has not been proven. ${ }^{13,19}$ Other suggestions for improvement have included quantifying doses in terms of tablets or volume in standard measures, avoiding foreign words, using short and precise information only, and avoiding nonquantifiable statements. ${ }^{11,47}$

Cultural differences should also be considered, as it is known that different cultures may interpret pictograms and symbols differently. ${ }^{27}$ Although challenging, the goal is to provide information that is comprehensible to people of different cultures, ages, levels of education, and types of employment whenever possible. ${ }^{27}$

\section{Physicians: effective receipt and transmission of drug information}

Acknowledging the time constraints faced by physicians, it is important to use maximally effective communication strategies when educating physicians regarding updates in medication information. Information should be clinically based and relevant to daily patient care. Question and answer formats have been suggested, although not specifically studied for effectiveness. Use of web-based notifications via email or other electronic means should be encouraged. Educational efforts should promote greater awareness of medication side effects, management, and reporting. Education should be an ongoing process, and medical learners should be exposed many times during their educational experience through multiple means including clinical experiences, didactic lectures, and interaction with pharmacists. ${ }^{40}$

\section{Patient education}

Health professionals such as physicians and pharmacists must remember the vital role they play in educating patients of all backgrounds and literacy levels. Improving WMI and drug labels can improve comprehensibility of drug information and knowledge of side effects, but this is most useful in patients with adequate health literacy. Unfortunately, those with lower literacy levels seem to obtain minimal benefit from changes in WMI or drug labeling. ${ }^{21}$ It is therefore critically important for physicians and pharmacists to increase communication efforts with patients of lower literacy levels, as this may be their primary source of information. Educating consumers on the active ingredients of over-the-counter medications and the importance of reading drug labels may contribute to better knowledge. Patients perceive that over-the-counter prescriptions cannot cause harm..$^{48}$ This is a dangerous misconception that may be helped by ad campaigns, public health policy, and improved labeling on over-the-counter drugs.

As standards in WMI evolve, patients should be educated on the basics of interpreting drug information. For example, if standard pictograms or symbols are chosen for conveying the information, public advertisement campaigns and curriculum in school health classes can be used to disseminate the common standard. ${ }^{27}$ The goal of patient education is not only to reduce ADRs, but also to meet the increasing expectations that consumers are demanding of health care systems in general and physicians specifically. ${ }^{29}$

\section{Patients as informed consumers}

Government initiatives throughout Europe and the United States have encouraged personal responsibility of patients so they will be more involved in health care decisions and plans of care. ${ }^{13,49}$ At the level of drug administration, this requires patients to know more about their own medications. Ziegler et al found that 1905 of 2500 patients surveyed $(76.2 \%)$ at outpatient clinics in the US wanted their physicians to tell them about all possible side effects, regardless of how rare or how many potential side effects there may be. ${ }^{50}$ This task would be daunting for any physician, and if followed in the strictest sense, would make physicians ineffective and overburdened. The desire for drug information highlights the importance of patients taking some initiative in learning about medications independently. Interventions targeting patient self efficacy encourage patients to question providers regarding medications, seek information from pharmacists, utilize the information-rich internet to access viable medication information websites, 
and take time to read package leaflets. Although this may be cumbersome, the benefits to patients and their families are potentially great.

\section{Continuing challenges}

\section{Medication information in developing countries}

By necessity, the types of drug information supplied in developing countries in Asia have been quite different than that supplied in developed countries. ${ }^{51}$ Over time, available drug information in developing countries is becoming more comparable to that in most developed countries. However, the complexity of WMI in developed countries can be especially cumbersome for those in developing countries. Direct duplication of drug information from developed countries is not necessarily the standard in determining the appropriateness of drug information in developing countries. Rather than focusing on medication information, local health challenges (eg, tuberculosis, leprosy, or endemic tropical diseases), may take precedence.

Even if complete written medical information were available, literacy plays a significant role in the usefulness of WMI. Local customs and physician shortages may affect the nature of drug information supplied. The lack of literacy within many countries makes verbal, person-to-person dissemination of information the most effective means of communicating potential adverse side effects and appropriate methods of drug administration. ${ }^{51,52}$ The use of radio and sometimes television has become a more effective way of communicating drug and health information relating to local endemic problems. Detailed instructions with a series of pictograms and very few, simple words have been used to communicate drug information. No matter how the information is conveyed, adverse drug reaction information should be described in terms of severity, order of importance, and frequency. ${ }^{51}$

In an article proposing strategies for improving use of drugs in developing countries, Laing et al offer suggestions involving drug information and patient education. ${ }^{53}$ Pharmacists and drug marketers should be trained to offer useful advice on health and drugs. ${ }^{53}$ Results of studies in Indonesia, Kenya, Nepal, and the Philippines have shown improvement in the quality of practice when health care employees are trained in specifically targeted diseases. ${ }^{52,54}$ Consumer organizations and governments should be encouraged to promote education on drugs with advertising and patientoriented WMI that communicate clear statements of risk and potential adverse drug effects. ${ }^{53}$

\section{Conclusion}

This review has provided a discussion of the many challenges present in the communication of adverse drug reaction warnings to patients. The presence of adequate health literacy is a prerequisite for patients to understand written and verbal drug reaction warnings. Efforts to communicate verbally, emphasize laymen's language, utilize symbology in written medical information all show promise. Patients value medical information the most when it comes from the prescribing physician, but the expectation to receive counseling about all possible drug side effects is neither practical nor desirable. Too much information has the potential to frighten patients, encourage noncompliance, or dilute important and common side effects in a sea of information. One potential solution is to use a multidisciplinary approach when presenting drug warning information. The ideal approach would involve pharmacists and nurses and disease-specific counselors, whenever possible. Medication remains a key tool in modern medicine and patient safety is a top priority. Medications have the potential to both benefit and harm recipients. It follows that responsible use of medications requires effective communication of rationale for use, administration instructions, and potential harms. Additional research is needed to define best practices in communicating the likelihood of adverse events, balanced with the benefits provided by the drug, in order to enable consumers to make informed decisions regarding treatment of personal health issues.

\section{Acknowledgments}

The authors wish to thank Jason Ettlinger, Scott and White Publications Department, for his invaluable assistance with this paper.

\section{Disclosure}

No conflicts of interest were declared in relation to this paper.

\section{References}

1. Institute of Medicine. Preventing Medication Errors. In: Aspden P, Wolcott J, Bottman L, Cronenwett LR, editors. Washington, DC: National Academy Press; 2006.

2. Wolf MS, Davis TC, Tilson HH, Bass PF, Parker RM. Misunderstanding of prescription drug warning labels among patients with low literacy. $\mathrm{Am}$ J Health-Syst Pharm. 2006;63:1048-1055.

3. World Health Organization. International Drug Monitoring: The role of the hospital. Geneva, Switzerland: World Health Organization; 1969. Technical Report Series Nr 425:5-24.

4. Agency for Healthcare Research and Quality. US Department of Health and Human Services. Reducing and preventing adverse drug events to decrease hospital costs. Research in Action, Issue 1. Available at: http:// www.ahrq.gov/qual/aderia/aderia.htm. Accessed 2010 Oct 10. 
5. Rodriguez-Monguior R, Otero MJ, Rovira J. Assessing the economic impact of adverse drug effects. Pharmacoeconomics. 2003;21;623-650.

6. Lazarou J, Pomeranz BH, Corey PN. Incidence of adverse drug reactions in hospitalized patients: a meta-analysis of prospective studies. JAMA. 1998;279:1200-1205.

7. Sikdar KC, Alaghehbandan R, MacDonald D, et al. Adverse drug events in adult patients leading to emergency department visits. Ann Pharmacotherapy. 2010;44:641-649.

8. Pirmohamed M, James S, Meakin S, et al. Adverse drug reactions as a cause of admission to hospital: prospective analysis of 18,820 patients. BMJ. 2004;329:15-19.

9. Forster AJ, Murff HJ, Peterson JF, Gandhi TK, Bates DW. Adverse drug events occurring following hospital discharge. J Gen Intern Med. 2005;20:317-323.

10. Carrigan N, Raynor DK, Knapp P. Adequacy of patient information on adverse effects: an assessment of patient information leaflets in the UK. Drug Safety. 2008;31:305-312.

11. Fuchs J, Hippius M, Schaefer M. Analysis of German package inserts. Int J Clin Pharmacol Ther. 2006;44:8-13.

12. Wallace LS, Keenum AJ, Roskos SE, Blake GH, Colwell ST, Weiss BD. Suitability and readability of consumer medical information accompanying prescription medication samples. Patient Educ Couns 2008;70:420-425.

13. Twomey C. An analysis of patient information leaflets supplied with medicines sold by pharmacists in the United Kingdom. Library Inf Res News. 2001;25:3-12.

14. Bernardini C, Ambrogi V, Fardella G, Perioli L, Grandolini G. How to improve the readability of the patient package leaflet: a survey on the use of colour, print size, and layout. Pharmacol Res. 2001;43: 437-443.

15. Lokker N, Sanders L, Perrin EM, et al. Parental misinterpretations of over-the-counter pediatric cough and cold medication labels. Pediatrics. 2009;123:1464-1471.

16. Yin HS, Johnson M, Mendelsohn AL, Abrams MA, Sanders LM, Dreyer BP. The health literacy of parents in the United States: a nationally representative study. Pediatrics. 2009;124:S289-S298.

17. Wolf MS, Davis TC, Bass PF, et al. Improving prescription drug warnings to promote patient comprehension. Arch Intern Med. 2010 170:50-56.

18. Davis TC, Wolf MS, Bass PF, et al. Low literacy impairs comprehension of prescription drug warning labels. J Gen Intern Med. 2006; 21:847-851.

19. Peregrin T. Picture this: visual cues enhance health education messages for people with low literacy skills. J Am Diet Assoc. 2010; 110:500-505.

20. Shrank WH, Patrick A, Gleason PP, et al. An evaluation of the relationship between the implementation of a newly designed prescription drug label at Target pharmacies and health outcomes. Med Care. 2009 47:1031-1035.

21. Davis TC, Federman AD, Bass PF, et al. Improving patient understanding of prescription drug label instructions. J Gen Intern Med. 2008; 24:57-62.

22. Morris LA. A survey of patients' receipt of prescription drug information. Med Care. 1982;20:596-605.

23. Griffin JP, Griffin JR. Informing the patient. J R Coll Physicians Lond. 1996;30:107-111.

24. Wilbur K, Salam SE, Mohammadi E. Patient perceptions of pharmacist roles in guiding self-medication of over-the-counter therapy in Qatar Patient Prefer Adherence. 2010;4:87-93.

25. Nader F, Mousavizadeh K, Ghafourifar P. Patient sources for drug information in Iran: a questionnaire-based survey. Pharm World Sci. 2008;30:764-767.

26. Hughes L, Whittlesea C, Luscombe D. Patients' knowledge and perceptions of the side-effects of OTC medication. J Clin Pharm Ther. 2002;27:243-248
27. Bernardini C, Ambrogi V, Perioli L, Tiralti MC, Fardella G. Comprehensibility of the package leaflets of all medicinal products for human use: a questionnaire survey about the use of symbols and pictograms. Pharmacol Res. 2000;41:679-688.

28. Vander Stichele RH, van Haecht CHV, Braem MD, Bogaert MG. Attitude of the public toward technical package inserts for medication information in Belgium. Ann Pharmacother. 1991;25:1002-1006.

29. Cullen G, Kelly E, Murry FE. Patients' knowledge of adverse reactions to current medications. Br J Clin Pharmacol. 2006;62:232-236.

30. Koo MM, Krass I, Aslani P. Patient characteristics influencing evaluation of written medicine information: lessons for patient education. Ann Pharmacother. 2005;39:1434-1440.

31. Bosworth HB. Challenges and strategies to improve patient health literacy and competencies. Patient Intelligence. 2010;2:19-25.

32. Nielsen-Bohlman LN, Panzer AM, Kindig DA, editors. Health Literacy: A prescription to end confusion. Washington, DC: National Academies Press; 2004

33. Osterberg L, Blaschke T. Adherence to medication. NEngl JMed. 2005: 353:487-497.

34. Powers B, Bosworth HB. Revisiting literacy and adherence: future clinical and research directions. $J$ Gen Intern Med. 2006;21:823-828.

35. Wolf MS, Davis TC, Shrank W, et al. To err is human: patient misinterpretations of prescription drug label instructions. Patient Educ Couns. 2007;67:293-300.

36. Davis TC, Wolf MS, Bass PF, et al. Literacy and misunderstanding prescription drug labels. Ann Int Med. 2006;145:887-894.

37. Bailey SC, Pandit AU, Curtis L, Wolf MS. Availability of Spanish prescription labels: a multi-state pharmacy survey. Med Care. 2009;47: 707-710.

38. Stewart KA, Natske BM, Williams T, Granger E, Ward Casscells S, Croghan TW. Temporal trends in anti-diabetes drug use in tricare following safety warnings in 2007 about rosiglitazone. Pharmacoepidemiol Drug Saf. 2009;18:1048-1052.

39. Canadian Medical Association Journal. Anti-psychotic drug use in the elderly increases despite drug safety warnings. Media Release: 25 Aug 2008. Available from: http://www.eurekalert.org. Accessed 2010 Oct 11

40. Goldman SA. Communication of medical product risk: how effective is effective enough? Drug Saf. 2004;27:519-534.

41. May FW, Rowett DS, Gilbert AL, McNeece JI, Hurley E. Outcomes of an educational-outreach service for community medical practitioners: non-steroidal anti-inflammatory drugs. Med J Aust. 1999; 170: 471-474.

42. European Commission. EEC Directive 92/27/EEC on labeling of medicinal products for human use and on package leaflets (OJ Nr L113 of 1992 Apr 30). Brussels, Belgium: EC Pharmaceuticals Committee; 1992.

43. European Commission. A Guideline on the Readability of the Label and Package Leaflet of Medicinal Products for Human Use. Brussels, Belgium: EC Pharmaceuticals Committee; 1998.

44. European Commission. A Guideline on the Readability of the Label and Package Leaflet of Medicinal Products for Human Use. Brussels, Belgium: EC Pharmaceuticals Committee, 2009.

45. Keystone Center. The Final Report of the Keystone National Policy Dialogue on Food, Nutrition, and Health. Washington DC: Keystone Center; 1996.

46. Webb J, Davis TC, Bernadella P, et al. Patient-centered approach for improving prescription drug warning labels. Patient Educ Couns. 2008;72:443-449.

47. Fuchs J, Hippius M. Inappropriate dosage instructions in package inserts. Patient Educ Couns. 2007;67:157-168.

48. Roumie CL, Griffin MR. Over-the counter analgesics in older adults: a call for improved labelling and consumer education. Drugs Aging. 2004;21:485-498.

49. Healthy People 2010. Available from: http://www.healthypeople.gov/ Document/tableofcontents.htm. Accessed 2010 Oct 11. 
50. Ziegler DK, Mosier MC, Buenaver M, Okuyemi K. How much information about adverse effects of medication do patients want from physicians? Arch Intern Med. 2001;161:706-713.

51. de Maar EW, Kshirsagar NA, Darmansjah I. An Asian perspective on drug and related health care information. Drug Inf J. 1983;17: 263-269.

52. Kafle KK, Bhuju GB, Karkee SB, et al. An intervention improving prescribing practices and monitoring drugs availability in a district. Nepal Med Coll J. 2009;11:217-221.
53. Laing RO, Hogerzeil HV, Ross-Degnan D. Ten recommendations to improve use os medicines in developing countries. Health Policy Plan. 2001;16:13-20.

54. Ross-Degnan D, Soumerai S, Goel PK, et al. The impact of face to face educational outreach on diarrhea treatment in pharmacies. Health Policy Plan. 1996;11:308-318.

\section{Publish your work in this journal}

Patient Intelligence is an international, peer-reviewed, open access journal that characterizes and measures the central role of patient behavior and intention in optimizing healthcare management in all areas of disease and complaint types. An improved understanding of patient intelligence coupled with predictive analysis helps an organization contribute more effectively to achieving better outcomes.

Submit your manuscript here: http://www.dovepress.com/patient-intelligence-journal

\section{Dovepress}

The journal is characterized by the rapid reporting of reviews, original research, methodologies, analytics, modeling, clinical studies and patient surveys across all disease areas. The manuscript management system is completely online and includes a very quick and fair peer-review system. Visit http://www.dovepress.com/ testimonials.php to read real quotes from published authors. 